\title{
The Social Organization of Interpretation
}

\author{
Comment \\ by \\ JENS BECKERT

I have read Arndt Sorge's paper (SORGE [2006]) with great interest and great joy. I believe that it is a rich paper that addresses some core issues in organization theory as well as social theory in general. I agree with most of what Sorge is arguing. This does not make it easy to comment on the paper, at least if the expectation is that the commentator will take a counterposition.

My comments focus on two points. First, I will state what I take to be Arndt Sorge's main argument and where I see his contribution to our understanding of organizational behavior. Then I will concentrate on the last section of their paper. I believe that this section - which discusses how to connect the interpretative role of organizational actors with templates prevalent in social settings - needs a stronger incorporation of social influences on actors' interpretations.

Let me start with the first point: the value of Sorge's argument for organization theory. Population ecology and the new institutionalism are two powerful approaches in organization theory. Both approaches can be understood largely as reactions to the paradigm of contingency theory, which dominated much of organization theory until the 1980s. In a nutshell, contingency theorists claim that organizations respond to changing environmental conditions with flexible, functional adaptations based on rational decisions made by organizational actors. Population ecologists (HANNAN AND FREEMAN [1977]) and institutionalists (MEYER AND Rowen [1977]; DiMAGGio AND Powell [1983]) tackle the question of how situative fits can emerge if not through rational action. Both approaches maintain, though based on different arguments, that the idea of flexible adaptation is flawed. Empirical studies show that organizational structures tend to be sticky. And, as surprising as this may be for contingency theorists, organizations are well served by avoiding continual adaptations, which could cause them to lose their specific resource endowments (population ecology) or endanger 
the legitimacy derived from their fit within an organizational field (institutionalism).

The alleged isomorphism of organizational structures leads at the same time to a profound problem for organization theory. What is the role of efficiency and "strategic choice" (CHILD [1972]) in organizational behavior? Or, to put it differently: What is the role of contingency theory? This question sparked substantial debate in the 1990s when institutionalists incorporated strategic agency into their models by introducing the concept of an institutional entrepreneur (DIMAGGIO [1988]; GREENWOOd AND Hinnings [1996]; BECKERT [1999]; DORADO [2005]).

While Sorge is sympathetic to this debate, he does find it limited. The theoretical alternatives force researchers into an either-or decision that overlooks the inherently dilemmatic character of institutions. We need to understand institutions as being simultaneously enabling and constraining entities. Once we do this, it becomes possible to preserve and combine valid insights from contingency theory, population ecology, and institutional organization theory. Sorge does not view this as a new theoretical synthesis but rather as an approach that attempts to stimulate dialogue between different theoretical positions.

It is from this theoretical consideration that Sorge turns to an interactionist interpretation of institutions that is largely based on the phenomenological concept of typifications. Behavior is necessarily institutional because it is only through the intersubjective construction of meaning in typifications that action becomes possible. At the same time, institutions are constructed through interactions that take place as negotiations between actors. These are insights that have been part of sociology since the 1960s and can be found, for instance, in the works of Harold Garfinkel and - within the context of the investigation of organizations - in the negotiated-order approach (STRAUSS [1978]).

Understanding institutions from an interactionist perspective provides important insights into the regularities of social action and the "agent dependency" of institutions. This responds to crucial issues within institutional theory: Not considered an objective constraint guiding action in unequivocal ways, institutions are necessarily open to and emerge from the contingent interpretations of actors. They are not prescriptive enough to determine action. Hence institutional rules must be interpreted by actors before they can exercise a regulatory function on behavior. This helps us understand why institutions change even when institutional actors' sole intent is to reproduce the institution (STREECK AND THELEN (eds.) [2005]), and it gives justification to a perspective on organizational reproduction and change that sees it as the result of constantly ongoing negotiations between actors. 
Up to this point I find it easy to follow Arndt Sorge. The part I view more critically is the last part of the paper. The problem Sorge poses under the heading "Organizing as a Societal Phenomenon" can be stated as follows: If institutions are enacted realities depending on the contingent interpretations of actors, it seems hardly possible that they can help stabilize social interaction in organizations beyond the limited range of face-to-face interaction. Sorge is aware of this problem, which had already been an issue of debate in the 1960s with reference to the interpretative paradigm. How could such an approach go beyond the narrow confines of microsociology?

The way Sorge deals with this problem I find only partially satisfying: He rightfully rejects solutions that refer to the role of norms and values in a society or propose cultural traits in the sense of national characteristics, amounting to a Volksgeist. To talk of a homogeneous culture has no basis in modern differentiated societies. The alternatives Sorge mentions remain, however, too vague. Giddens's notion of the reciprocal constitution of micro- and macrostructures, to which Sorge refers, is largely declaratory but not explanatory and does away with structures as an analytically independent entity (ARCHER [1982]). The assertion that "[t]he coherence of society is founded upon meaningful interdependences between different institutions in different situations" (SORGE [2006, p. 185]) does not suffice to explain how institutionalization is embedded in macrostructures.

Let me clarify what I mean by this. I follow Sorge in believing that institutions become relevant only through their enactment. This enactment, however, is subject to structuring influences that go beyond the acting individuals. Actors do have an intersubjective basis in taken-for-granted belief structures that form within certain boundaries within a society or an organization. These belief structures are relevant with regard to the formation of interests, the consideration of values, and path dependences. Ann SWIDLER's [1986] notion of "culture as a tool box" suggests that actors apply their cultural repertoire in situationally specific ways; there are individual distinctions in cultural practices. But the tool box contains just a limited number of tools. There are "socially available meaning systems [that] privilege the importance and symbolic weight of some distinctions over others" (LAMONT AND THÉVENOT [2001, p. 9]). Following DURKHEIM AND MAUSS [1963], we can talk here about classification systems that organize patterns of perception socially and thus draw cognitive and normative boundaries. The task at hand is to systematically identify existing classifications and the ways in which they shape the enactment of institutions.

This has been a core issue in the new comparative cultural sociology (LAMONT AND THÉVENOT [2001]), which sees interest formation and actor strategies as connected to cognitive and cultural frames. Due to the multidimensionality of interests and the complexity of causal relations as well as unintended consequences, actors are confronted with "critical situations" (THÉVENOT [2002, p. 181]). In such situations of fundamental uncertainty, the question of how actors enact institutions can only be answered with recourse to their beliefs or ideas on cause-effect rela- 
tionships, which are culturally shaped (BECKERT [2002]; BLYTH [2002]; DOBBIN [1994]; SWIDLER [1986]). Comparative cultural sociology uses notions like "regulatory style" (DOBBIN [1994]) or "orders of justification" (LAMONT AND THÉVENOT [2001]) to characterize these cultural reference points.

This is not intended to question the crucial role Sorge assigns to interpretations. I do argue, however, that sociology must find sociological explanations for the kind of typifications it observes in organizations and society at large. One way of looking at this problem is to view interpretations as shaped by culturally anchored repertoires. The repertoires form a cognitive background from which problems are perceived and propositions for specific typifications are justified. Hence action takes place in a culturally structured field of legitimate normative goals and social values as well as specific perceptions of causal relations by which actors conceive consequences. In this sense, repertoires lead to specific forms of organizing, while others are not even regarded as serious alternatives. This does not advocate a position of cultural determinism. While the orders of justification provide a frame for the perception of problems, they must be interpreted by actors and will be confronted with contradictory positions available in the discursive field. This demonstrates the importance of the creative role of actors and the indeterminacy of outcomes. The significance of culture is thus seen essentially in the contribution of general systems of meaning to the fundamental views of social order and action strategies that prevail in social groups (DOBBIN [1994, p. 2]; LAMONT AND THEVÉNOT [2001]).

\section{References}

ARCHER, M. [1982], "Morphogenesis versus Structuration: On Combining Structure and Action," British Journal of Sociology, XXXIII, 4, 455-483.

BECKERT, J. [1999], "Agency, Entrepreneurs, and Institutional Change: The Role of Strategic Choice and Institutionalized Practices in Organizations," Organization Studies, 20, 777799.

[2002], "Von Fröschen, Unternehmensstrategien und anderen Totems: Die soziologische Herausforderung der ökonomischen Institutionentheorie?" pp. 133-147 in: A. Maurer and M. Schmid (eds.), Neuer Institutionalismus: Zur soziologischen Erklärung von Organisation, Moral und Vertrauen, Campus: Frankfurt/Main.

BLYTH, M. [2002], Great Transformations: Economic Ideas and Institutional Change in the Twentieth Century, Cambridge University Press: Cambridge.

ChILD, J. [1972], "Organizational Structure, Environment and Performance: The Role of Strategic Choice," Sociology, 6, 1-22.

DiMaggio, P. [1988], "Interest and Agency in Institutional Theory," pp. 3-22 in: L. Zucker (ed.), Institutional Patterns and Organizations, Ballinger: Cambridge, MA.

- - AND W. POWELL [1983], "The Iron Cage Revisited: Institutional Isomorphism and Collective Rationality in Organizational Fields," American Sociological Review, 48, $147-160$.

DовBIN, F. [1994], Forging Industrial Policy, Cambridge University Press: Cambridge. 
Dorado, S. [2005], "Institutional Entrepreneurship, Partaking, and Convening," Organization Studies, 26, 385-414.

Durkheim, E., AND M. MAuss [1963], Primitive Classification, University of Chicago Press: Chicago.

GReENwoOd, R., AND C. R. Hinnings [1996], "Understanding Radical Organizational Change: Bringing Together the Old and the New Institutionalism," Academic Management Review, 21, 1022-1054.

Hannan, M., AND J. FReEman [1977], "The Population Ecology of Organizations," American Journal of Sociology, 82, 929-964.

LAmONT, M., AND L. THÉVENOT [2001], "Introduction: Toward a Renewed Comparative Cultural Sociology," pp. 1-22 in: M. Lamont and L. Thévenot (eds.), Rethinking Comparative Cultural Sociology: Repertoires of Evaluation in France and the United States, Cambridge University Press: Cambridge.

MEYeR, J. W., AND B. Rowen [1977], "Institutionalized Organizations: Formal Structure as Myth and Ceremony," American Journal of Sociology, 83, 340-363.

Sorge, A. [2006], "Organizing Socially Constructed Internal and External Resources," Journal of Institutional and Theoretical Economics, 162, 172-193.

StrAuSS, A. [1978], Negotiations: Varieties, Processes, Contexts, and Social Order, JosseyBass: San Francisco.

StreecK, W., AND K. Thelen (eds.) [2005], Beyond Continuity: Institutional Change in Advanced Political Economies, Oxford University Press: New York.

Swidler, A. [1986], "Culture in Action: Symbols and Strategies," American Sociological Review, 51, 273-286.

THÉVENOT, L. [2002], "Conventions of Co-Ordination and the Framing of Uncertainty," pp. 181-197 in: E. Fullbrock (ed.), Intersubjectivity in Economics: Agents and Structures, Routledge: London.

Jens Beckert

Max-Planck-Institut

für Gesellschaftsforschung

Paulstr. 3

50676 Köln

Germany

E-mail:

beckert@mpifg.de 